\title{
Prevalence and species identification of Cryptosporidium spp. in the newborn dairy calves from Muang District, Khon Kaen Province, Thailand
}

\author{
Phennarin Doungmala ${ }^{1}$, Patchara Phuektes ${ }^{2}$, Weerapol Taweenan ${ }^{2}$, Somboon Sangmaneedet ${ }^{2}$ and Ornampai Japa ${ }^{3}$
}

1. Interdisciplinary Veterinary Science, Faculty of Veterinary Medicine, Khon Kaen University, Khon Kaen 40002 , Thailand; 2. Division of Pathobiology, Faculty of Veterinary Medicine, Khon Kaen University, Khon Kaen 40002, Thailand; 3. Department of Microbiology and Parasitology, Faculty of Medical Sciences, Phayao University, Phayao 56000, Thailand. Corresponding author: Phennarin Doungmala, e-mail: phennarin.d@gmail.com

Co-authors: PP: patphu@kku.ac.th,WT: wtaweenan@gmail.com, SS: sombn_sa@kku.ac.th, OJ: ornampai.ja@up.ac.th Received: 04-06-2019, Accepted: 20-08-2019, Published online: 23-09-2019

doi: 10.14202/vetworld.2019.1454-1459 How to cite this article: Doungmala P, Phuektes P, Taweenan W, Sangmaneedet S, Japa O (2019) Prevalence and species identification of Cryptosporidium spp. in the newborn dairy calves from Muang District, Khon Kaen Province, Thailand, Veterinary World, 12(9): 1454-1459.

\begin{abstract}
Aim: This study aims to determine the prevalence of Cryptosporidium spp. infection and to identify the species of Cryptosporidium spp. in newborn dairy calves between December 2016 and March 2017 in Muang District, Khon Kaen Province, Thailand.

Materials and Methods: A total of 200 fecal samples from newborn dairy calves of the ages 1 day up to 28 days were collected and the presence of Cryptosporidium oocysts was examined microscopically using the modified Kinyoun's acidfast staining technique. Then, Cryptosporidium species were identified using nested polymerase chain reaction amplification of $18 \mathrm{~S}$ rRNA gene and sequencing.

Results: The modified Kinyoun's acid-fast staining revealed the presence of Cryptosporidium oocysts in 51\% (102/200). Sequence analysis of the $18 \mathrm{~S}$ rRNA gene identified two species, namely, Cryptosporidium bovis $(\mathrm{n}=11)$ and Cryptosporidium ryanae $(\mathrm{n}=11)$ and one isolated strain could not be identified.

Conclusion: This study indicated that newborn dairy calves aging up to 4 weeks were highly infected with Cryptosporidium spp., and the infection mostly occurred in diarrheic dairy calves. This is the first report of Cryptosporidium in dairy calves in Khon Kaen Province and the results provide baseline information for further studies and control of Cryptosporidium infection in dairy calves in the study area.
\end{abstract}

Keywords: Cryptosporidium, Khon Kaen Province, nested polymerase chain reaction, newborn dairy calves, prevalence.

\section{Introduction}

Cryptosporidiosis is an important zoonotic disease caused by Cryptosporidium spp. transmitted among humans and animals. The disease is distributed worldwide including Thailand and has been found in cattle, goats, sheep, horses, pigs, dogs, cats, mice, chickens, turkeys, ducks, fishes, reptiles, wildlife, and in humans [1-3]. Cryptosporidium causes diarrhea in young animals due to their low immunity [4], especially in newborn dairy calves of 1-3 weeks of age [5]. The most important Cryptosporidium species causing economic losses is Cryptosporidium parvum. Cryptosporidium spp. parasitize the intestinal epithelium of mammals and other vertebrate hosts causing diarrhea similar to coccidian infection. The infected hosts shed Cryptosporidium oocysts in their feces [6]. Disease transmission mainly occurs through ingestion of water and food contaminated with

Copyright: Doungmala, et al. Open Access. This article is distributed under the terms of the Creative Commons Attribution 4.0 International License (http://creativecommons.org/licenses/ by/4.0/), which permits unrestricted use, distribution, and reproduction in any medium, provided you give appropriate credit to the original author(s) and the source, provide a link to the Creative Commons license, and indicate if changes were made. The Creative Commons Public Domain Dedication waiver (http:// creativecommons.org/publicdomain/zero/1.0/) applies to the data made available in this article, unless otherwise stated. oocysts [7]. Clinical signs of infected hosts depend on their immune status. Diarrhea may be in hosts having a strong immunity to the protozoa recover from diarrhea spontaneously. Clinical signs of cryptosporidiosis in neonatal dairy calves may vary from none to severe diarrhea accompanied by other signs such as depression, anorexia, fever, and severe dehydration [7]. Cryptosporidium infections in humans and animals are often neglected, with attention being paid only when hosts suffer from chronic severe diarrhea. Oocysts of Cryptosporidium can be detected in the feces of the immunosuppressed calves and humans. People working in dairy farms may be infected with Cryptosporidium through ingestion of food and water contaminated with oocysts. The infected hosts excrete oocysts in diarrheal feces [6].

Four major species of Cryptosporidium have been described as the bovine pathogen; Cryptosporidium andersoni, Cryptosporidium bovis, C. parvum, and Cryptosporidium ryanae [8-10]. Although it is rare, some other Cryptosporidium species have been found in cattle; Cryptosporidium felis in cow [11], Cryptosporidium hominis in a 3-day-old calf and 6-year-old cow from Scotland [12], and Chlamydia suis in a calf $[11,13]$. In livestock, only $C$. parvum is associated with clinical signs of unweaned calves (less 
than 6 weeks), C. bovis and C. ryanae are generally more common than $C$. parvum in post-weaned calves (1.5 months-11 months) without causing disease or any clinical signs. C. andersoni is considered the main pathogenic species, causing sporadic cases and outbreaks in the digestive glands of abomasum of older calves and adult cattle and has been shown to reduce dairy production. Infected cattle do not develop diarrhea but show clinical signs of reduced weight gain and milk yield and can excrete oocysts for several months.

The occurrence and species infection rate of Cryptosporidium infections in Thailand are not thoroughly investigated. Due to its zoonotic potential, this study aims to reveal the incidence of Cryptosporidium infection in dairy calves from Muang District, Khon Kaen Province and describes its association with age groups and identifies species of Cryptosporidium spp. The results of this study may provide useful information for the future research on prevention, control, and treatment of this important neglected disease in newborn dairy calves.

\section{Materials and Methods}

\section{Ethical approval}

The present study was approved by the Animal Ethics Committee of Khon Kaen University, based on the Ethics of Animal Experimentation National Research Council of Thailand.

\section{Fecal sample collection and examination}

A total of 200 fecal samples from 49 Holstein dairy farms were collected, classified according to their age Group I (1-7 days) 50 samples, Group II (8-14 days) 50 samples, Group III (15-21 days) 50 samples, and Group IV (22-28 days) 50 samples and were taken randomly from eight villages (Noen Thong, Sumjan, NonLan, Khok Si, Hin Lad, Non, Subcharoen, and Kham Bon) of two subdistricts of Muang District, Khon Kaen Province, between December 2016 and March 2017. Subsequently, the fecal samples were collected directly from rectum using disposable latex gloves and kept in the labeled cleaned polyethylene bags and brought to the laboratory and refrigerated at $4{ }^{\circ} \mathrm{C}$ until examined (for a maximum of 3 days).

Fecal samples were examined microscopically using the modified Kinyoun's acid-fast staining technique (cold method, with reagent: Carbol fuchsin and methylene blue) for the detection of Cryptosporidium oocysts. With this cold Kinyoun's acid-fast method, Cryptosporidium oocysts will be stained pink to red to deep purple on a pale blue background, measuring 4-6 $\mu \mathrm{m}$ in diameter and some of the four sporozoites may be visible [14]. All fecal samples were stored at $-20^{\circ} \mathrm{C}$, without preservatives until used.

Total DNA was extracted from fecal samples using QIAamp DNA Stool Mini Kit (Qiagen, $\mathrm{GmbH}$, Germany), and species identification of Cryptosporidium was performed using nested polymerase chain reaction (nested PCR) analysis of $830 \mathrm{bp}$ fragment of the 18S rRNA gene [15]. The secondary PCR products were visualized using $1.5 \%$ agarose gel electrophoresis. PCR products were purified using QIAquick PCR Purification Kit (Qiagen, GmbH, Germany). Sequencing was performed in an automated DNA sequencer, the BigDye $^{\mathrm{TM}}$ Terminator v3.1 Cycle (Axil Scientific Pte Ltd., The Gemini, Singapore Science Park II, Singapore). The results of DNA sequences were compared with those in GenBank database, using the BLAST program (www.ncbi.nlm.nih.gov/blast).

Results were analyzed using Epi Info version 7.0 (CDC, USA). Descriptive statistics were used to determine the infection rate of Cryptosporidium infection in dairy calves. Comparison of infection rate of Cryptosporidium infection in different groups of dairy calves (location, age) was conducted using Chi-square test. $p<0.05$ was considered statistically significant.

\section{Results}

Cryptosporidium infection rate in different age groups of newborn dairy calves

Of 200 fecal samples from dairy calves, 102 (51\%) were Cryptosporidium positive by modified Kinyoun's acid-fast stain. Geographical variation of the infection rate is shown in Table-1.

Chi-square test, there was a significant difference in proportions of positive dairy calves among different villages and subdistricts $(\mathrm{p}<0.05)$.

Cryptosporidium spp. infection in 1-7-dayold dairy calves in six different regions of Muang District, Khon Kaen Province, was found almost all regions except non-village. The overall infection rate of Cryptosporidium spp. was $50 \%(0-80 \%)$ in this age group, and the infection rate of Cryptosporidium spp. was found highest in Khok Si village (80\%). In 8-14-day-old dairy calves in seven different regions of Muang District, Khon Kaen Province, the infection of Cryptosporidium spp. was found almost in all regions except Non-village and Kham Bon village, and the overall infection rate of Cryptosporidium spp.

Table-1: Cryptosporidium spp. infection rate of newborn dairy calves in eight villages.

\begin{tabular}{lcc}
\hline Location & $\begin{array}{c}\text { Microscopic } \\
\text { detection (\%) }\end{array}$ & $\begin{array}{c}\text { Nested PCR } \\
\text { detection (\%) }\end{array}$ \\
\hline Non Thon subdistrict & & \\
$\quad$ Hin Lad & $0 / 2(0)$ & $1 / 2(50.0)$ \\
Non & $2 / 8(25.0)$ & $1 / 8(12.5)$ \\
Subcharoen & $5 / 8(62.5)$ & $2 / 8(25.0)$ \\
Kham Bon & $8 / 11(72.7)$ & $3 / 11(27.3)$ \\
Subtotal & $15 / 29(51.7)$ & $7 / 29(24.1)$ \\
Ban Khao subdistrict & & \\
Noen Thong & $35 / 53(66.0)$ & $3 / 5(5.7)$ \\
Sumjan & $11 / 46(23.9)$ & $8 / 46(17.4)$ \\
Non Lan & $35 / 63(55.6)$ & $13 / 63(20.6)$ \\
Khok Si & $6 / 9(66.7)$ & $3 / 9(33.3)$ \\
Subtotal & $87 / 171(50.9)$ & $27 / 171(15.8)$ \\
Total & $102 / 200(51.0)$ & $42 / 200(21.0)$ \\
\hline PCR Polymerase
\end{tabular}

$\mathrm{PCR}=$ Polymerase chain reaction 
was $44 \%(0-100 \%)$. In 15-21-day-old dairy calves in six different regions of Muang District, Khon Kaen Province, the infection of Cryptosporidium spp. was found almost in all regions except Non-village and Subcharoen village, and the overall infection rate of Cryptosporidium spp. was 60\% (0-100\%). In 22-28-day-old group in seven different regions of Muang District, Khon Kaen Province, the infection of Cryptosporidium spp. was found highest almost all regions except Sumjan village, and the overall infection rate of Cryptosporidium spp. was 48\% (0-100\%) (Table-2). The infection rate of Cryptosporidium spp. of newborn calves of different age ranged from $44 \%$ to $60 \%$ by microscopic examination, whereas that by nested PCR detection ranged 16-26\% (Table-2). Chisquare test conferred no significant difference in the infection rate of dairy calves of different age groups ( $p>0.05)$.

\section{Identification of Cryptosporidium species by $18 \mathrm{~s}$ rRNA sequencing}

The molecular analysis of 200 fecal samples revealed that $42(21 \%)$ were positive for Cryptosporidium, which was far less than positive rate by microscopic analysis $51 \%$. By nested PCR,

Table-2: Prevalence of Cryptosporidium spp. in each age group of newborn dairy calves.

\begin{tabular}{lcc}
\hline Age group & $\begin{array}{c}\text { Microscopic } \\
\text { detection (\%) }\end{array}$ & $\begin{array}{c}\text { Nested PCR } \\
\text { detection (\%) }\end{array}$ \\
\hline Group I (1-7 days old) & $25 / 50(50.0)$ & $13 / 50(26.0)$ \\
Group II (8-14 days old) & $22 / 50(44.0)$ & $12 / 50(24.0)$ \\
Group III (15-21 days old) & $30 / 50(60.0)$ & $9 / 50(18.0)$ \\
Group IV (22-28 days old) & $24 / 50(48.0)$ & $8 / 50(16.0)$ \\
\hline
\end{tabular}

$\mathrm{PCR}=$ Polymerase chain reaction
42 samples were successfully amplified and were sequenced later. Sequence analysis from 23 readable electrophoregrams revealed that Cryptosporidium in the present study had $83-99 \%$ similarities with genotypes listed in Genbank: C. ryanae (11 strains) was detected in all age groups and found in almost every village except Khok Si, Non, and Subcharoen; C. bovis (11 strains) was detected only in age Groups I, II, and III and found in almost every village except Khok Si, Hin Lad, Non, and Kham Bon; and one unidentified species of Cryptosporidium spp. was detected in age Group I in Noen Thong. The rest of other Cryptosporidium nested PCR products demonstrated weak bands that could not be sequenced. $C$. parvum and $C$. andersoni were not found in this study (Table-3).

\section{Discussion}

In the study area, newborn dairy calves of age up to 4 weeks were highly infected with Cryptosporidium spp. The infection mostly occurred in diarrheic dairy calves, suggesting that, Cryptosporidium may be a major causative agent of diarrhea in young calves aged up to 4 weeks. Cryptosporidium infection causes retarded growth of calves or induces secondary infections with other microorganisms. Young calves or immunocompromised animals are susceptible to infection with Cryptosporidium spp. than adults $[2,4,5]$. A relatively high infection rate of Cryptosporidium spp. infection has been detected in dairy calves elsewhere, with the oocysts being detected, especially in dairy calves aged 1-3 weeks [5]. Highest shedding of Cryptosporidium oocysts occurred in dairy calves aged 3 weeks. The present study was the first identification

Table-3: Results of genotypic identification of Cryptosporidium spp. and accession against GenBank database.

\begin{tabular}{|c|c|c|c|}
\hline Species of Cryptosporidium & Accession and identity with GenBank (\%) & Location & Age group \\
\hline Cryptosporidium spp. (full sequence) & KF994564 (99) & Noen Thong & Group I \\
\hline C. ryanae (full sequence) & KJ020908 (99) & Hin Lad & Group I \\
\hline C. ryanae (full sequence) & KP793013 (99) & Sumjan & Group I \\
\hline C. bovis (partial sequence) & MG972763 (99) & Non Lan & Group I \\
\hline C. bovis (full sequence) & KF128742 (99) & Non Lan & Group I \\
\hline C. bovis (full sequence) & HQ179573 (99) & Non Lan & Group I \\
\hline C. ryanae (partial sequence) & KJ020908 (98) & Sumjan & Group I \\
\hline C. bovis (partial sequence) & MG972763 (98) & Subcharoen & Group II \\
\hline C. bovis (partial sequence) & MG972763 (92) & Subcharoen & Group II \\
\hline C.ryanae (partial sequence) & MF671875 (99) & Sumjan & Group II \\
\hline C. bovis (partial sequence) & MG972763 (99) & Sumjan & Group II \\
\hline C. ryanae (partial sequence) & KJ020908 (99) & Non Lan & Group II \\
\hline C. ryanae (partial sequence) & KJ020908 (99) & Kham Bon & Group II \\
\hline C. ryanae (partial sequence) & MF671875 (97) & Non Lan & Group II \\
\hline C. ryanae (partial sequence) & KJ020908 (99) & Non Lan & Group II \\
\hline C. bovis (partial sequence) & MG972763 (97) & Noen Thong & Group II \\
\hline C. bovis (partial sequence) & MG972763 (97) & Noen Thong & Group II \\
\hline C. ryanae (partial sequence) & KJ020908 (99) & Sumjan & Group II \\
\hline C. bovis (partial sequence) & MG972763 (97) & Non Lan & Group II \\
\hline C. ryanae (partial sequence) & MF671876 (98) & Noen Thong & Group III \\
\hline C. bovis (partial sequence) & MG972763 (99) & Noen Thong & Group III \\
\hline C. bovis (partial sequence) & MG972763 (83) & Non Lan & Group III \\
\hline C. ryanae (full sequence) & MF671875 (97) & Sumjan & Group IV \\
\hline
\end{tabular}

C. ryanae=Cryptosporidium ryanae, $C$. bovis=Cryptosporidium bovis 
of Cryptosporidium spp. infection in dairy calves in Muang District, Khon Kaen Province. In a total of 200 dairy calves investigated, microscopically positive with Cryptosporidium spp. (102/200 [51\%]) was higher than nested PCR (42/200 [21\%]), this may cause by inhibitors in feces that inhibit the activity of the enzyme; therefore, DNA could not be increased during the PCR process. The microscopy results were higher than previous studies in Thailand, i.e., $12.63 \%$ in Chiang Mai and Saraburi [16], 0.6\% in Nong Pho region of Central Thailand [17], 5\% in Chiang Mai, Chiang Rai, and Lumpang [18], and 0.5\% in Saraburi, Kanchanaburi, and Nakornpathom [19]. The infection rate of Cryptosporidium detected by nested PCR was higher than previous studies in Thailand, i.e., 7.6\% and $1.3 \%[18,19]$. The results of this study were in line with those previously reported in the other countries, the rates of Cryptosporidium spp. infection in pre-weaned dairy calves, $41.5 \%$ with being reported in France [20], 10.2\% in England [21], 25.2\% and 17.3\% in Ethiopia [22,23], 6.9\% in Egypt [24], 27.10\% in Eastern Algeria [25], 78.1\% in Nigeria [26], 22.3\%, $3.6 \%$, and $24-31 \%$ in Iran [27-29], $7.3 \%$ in Iraq [30], $1.39 \%, 15.6 \%, 14.4 \%$, and $6.4 \%$ in China $[31-34]$, $43.3 \%$ in Vietnam [35], 82\% in Myanmar [36], 3.2\% in Malaysia [37], and $37.25 \%$ in India [38]. Age of animal is an important factor in infection with Cryptosporidium spp., for example, calves are commonly more susceptible than cows to infection [39]. The subclinically infected ruminants and cows can be carriers and transmit Cryptosporidium spp. to calves. The variance of infection rates depended on the geographical and environmental variations, management of cares, and hygiene in the farms [40]. The high rate of Cryptosporidium infection in newborn dairy calves in this study indicates that more attention should be paid to Cryptosporidium spp. in dairy farms to prevent diarrhea in young animals and their potential transmission to humans.

Species of Cryptosporidium were determined in calves and some of them have been identified as zoonotic pathogens [41]. The results of the genotyping of Cryptosporidium spp. using nested PCR and DNA sequencing revealed that some samples in this study were positive for C. bovis and C. ryanae, both of which can infect only cattle, although they are not pathogenic to cattle. In this study, C. andersoni was not detected. This species has been reported in adult cattle only and rarely detected in the pre-weaned animals $[21,42]$. C. parvum, which is known as zoonotic species and infects both farm animals and humans [43], was also not found in this study. In Thailand, the presence of C. parvum and C. bovis in cattle was demonstrated by sequencing analysis in the previous study $[18,19]$. Since asymptomatic cattle infected with $C$. parvum can be the main reservoir of disease, we should pay attention to the control and prevention of this infection both in humans and animals to avoid mutual transmission between humans and animals.
This is the first study of infection rate of Cryptosporidium spp. in dairy calves in Muang District, Khon Kaen province, Thailand. This study revealed the overall Cryptosporidium infection rate of $51 \%(102 / 200)$ with microscopic examination and $21 \%(42 / 200)$ with nested PCR. Genotype analysis revealed that only two species, C. ryanae and C.bovis, were present in the study area. Since the variety of species of Cryptosporidium in Thailand is still unclear in each region, baseline information for the diversity of this organism with molecular epidemiology in relation to clinical symptoms is required for the control of Cryptosporidium infection.

\section{Conclusion}

This study is the first report of Cryptosporidium infection in the newborn dairy calves in Khon Kaen province, Thailand. The newborn dairy calves aging up to 4 weeks were highly infected with $C$. ryanae or $C$. bovis, and diarrhea was associated with the Cryptosporidium-infected dairy calves.

\section{Authors' Contributions}

PD collected the samples, analyzed the data, and wrote the manuscript. PP and OJ applied PCR testing. WT and SS designed the study and approved the final manuscript.

\section{Acknowledgments}

We would like to thank Thailand One Health University Network and Faculty of Veterinary Medicine, Khon Kaen University, Thailand, for providing a research grant (AID-OAA-A-15-00014) and also thank veterinarians of the Department of Livestock Development and staffs of Khon Kaen Dairy Cooperation for their help in sample collection.

\section{Competing Interests}

The authors declare that they have no competing interests.

\section{Publisher's Note}

Veterinary World remains neutral with regard to jurisdictional claims in published institutional affiliation.

\section{References}

1. Fayer, R., Gasbarre, L., Pasquali, P., Canals, A., Almeria, S. and Zarlenga, D. (1998a) Cryptosporidium parvum infection in bovine neonates: Dynamic clinical, parasitic and immunologic patterns. Int. J. Parasitol., 28(1): 49-56.

2. Nydam, D.V., Wade, S.E., Schaaf, S.L. and Mohammed, H.O. (2001) Number of Cryptosporidium parvum oocysts or Giardia spp. Cysts shed by dairy calves after natural infection. Am. J. Vet. Res., 62(10): 1612-1615.

3. Saini, P.K., Ransom, G. and McNamara, A.M. (2000) Emerging public health concerns regarding cryptosporidiosis. J. Am. Vet. Med. Assoc., 217(5): 658-663.

4. Nydam, D.V. and Mohammed, H.O. (2005) Quantitative risk assessment of Cryptosporidium species infection in dairy calves. J. Dairy Sci., 88(11): 3932-3943.

5. Fayer R., Trout, J.M. and Jenkins, M.C. (1998) Infectivity 
of Cryptosporidium parvum oocysts stored in water at environmental temperatures. J. Parasitol., 84(6): 1165-1169.

6. Cooney, M.A. (2009) Relationship between Fecal and Oocyst Shedding in Dairy Calves Challenged with Cryptosporidium parvum. PhD.Dissertation. Cornell University, USA. Available from: https://hdl.handle. net/1813/13077. Last accessed on 17-09-2019.

7. Castro-Hermida, J.A., Gonzalez-Losada, Y.A., MezoMenendez, M. and Ares-Mazas, E. (2002) A study of Cryptosporidium parvum in a cohort of neonatal calves. Vet. Parasitol., 106(1): 11-17.

8. Langkjaer, R.B., Vigre, H., Enemark, H.L. and MaddoxHyttel, C. (2007) Molecular and phylogenetic characterization of Cryptosporidium and Giardia from pigs and cattle in Denmark. Parasitology, 134(3): 339-350.

9. $\quad$ Feng, Y., Ortega, Y., He, G., Das, P., Xu, M. and Zhang, X. (2007) Wide geographic distribution of Cryptosporidium bovis and the deer-like genotype in bovines. Vet. Parasitol., 144(1-2): 1-9.

10. Fayer, R., Santin, M. and Trout, J.M. (2007a) Infection rate of Cryptosporidium species and genotypes in mature dairy cattle on farms in Eastern United States compared with younger cattle from the same locations. Vet. Parasitol., 145(3-4): 260-266.

11. Bornay-Llinares, F.J., da Silva, A.J., Moura, I.N.S., Myjak, P., Pietkiewicz, H. and Kruminis-Lozowska, W. (1999) Identification of Cryptosporidium felis in a cow by morphologic and molecular methods. Appl. Environ. Microbiol., 65(4): 1455-1458.

12. Smith, R.P., Nichols, R.A., Mallon, M., MacLeod, A., Tait, A. and Reilly, W.J. (2005) Natural Cryptosporidium hominis infections in Scottish cattle. Vet. Rec., 156(22): 710-711.

13. Fayer, R., Santin, M., Trout, J.M. and Greiner, E. (2006) Infection rate of species and genotypes of Cryptosporidium found in 1-2-year-old dairy cattle in the Eastern United States. Vet. Parasitol., 135(2): 105-112.

14. Ma, P. and Soave, R. (1983) Three-step stool examination for cryptosporidiosis in 10 homosexual men with protracted watery diarrhea. J. Infect. Dis., 147(5): 824-828.

15. Xiao, L., Sing, A., Limor, J., Graczyk, T.K, Gradus, S. and Lal, A.A. (2001) Molecular characterisation of Cryptosporidium oocysts in samples of raw surface water and wastewater. Appl. Environ. Microbiol., 67(3): 1091-1101.

16. Bamrung, M., Monya, E. and Suree, T. (1991) Preliminary studies on protozoa, Cryptosporidium in cattle, buffalo. Vet. Med., 42(3): 123-128.

17. Jittapalapong, S., Pinyopanuwat, N., Chimnoi, W., Siripanth,C. and Stich, R.W. (2006) Prevalence of Cryptosporidium among dairy cows in Thailand. Ann. N. Y. Acad. Sci., 1081(1): 328-335.

18. Inpankaew, T., Jiyipong, T., Sunanta, C., Kengradomkij, C., Pinyopanuwat, N. and Jittapalapong, S. (2017) Prevalence and molecular characterization of bovine Cryptosporidium from dairy cows in Northern Thailand. Acta Parasitol., 62(4): 772-774.

19. Inprankaew, T., Arunvipas, P., Pinyopanuwat, N., Chimnoi, W. and Jittapalapong, S. (2009) Prevalence, risk factors and genotyping of Cryptosporidium spp. from feces of dairy cows in Saraburi, Kanchanaburi and Nakhon Pathom province. Kasetsart. J. (Nat. Sci.), 43(5): 58-62.

20. Delafosse, A., Chartier, C., Dupuy, M.C., Dumoulin, M., Pors, I. and Paraud, C. (2015) Cryptosporidium parvum infection and associated risk factors in dairy calves in Western France. Prev. Vet. Med., 118(4): 406-412.

21. Smith, R.P., Clifton-Hadley, F.A., Cheney, T. and Giles, M. (2014) Prevalence and molecular typing of Cryptosporidium in dairy cattle in England and Wales and examination of potential on-farm transmission routes. Vet. Parasitol., 204(3-4): 111-119.

22. Wegayehu, T., Karim, R., Anberber M., Adamu, H., Erko, B., Zhang, L. and Tilahun, G. (2016) Prevalence and genetic characterization of Cryptosporidium species in dairy calves in Central Ethiopia. PLoS One, 11(5): e0154647.

23. Ayele, A., Seyoum, Z. and Leta, S. (2018) Cryptosporidium infection in bovine calves: Prevalence and potential risk factors in Northwest Ethiopia. BMC Res. Notes, 11(1): 105.

24. Mahfouz, M.E, Mira, N. and Amer, S. (2014) Prevalence and genotyping of Cryptosporidium spp. in farm animals in Egypt. J. Vet. Med. Sci., 76(12): 1569-1575.

25. Hocine, A.R., Bouzid, R., Ladjama, M. and Khalef, D. (2016) Prevalence of Cryptosporidium oocysts in calves in two areas from Eastern Algeria. J. Glob. Vet., 17(4): 335-342.

26. Akinkuotu, O.A., Fagbemi, B.O., Otesile1, E.B., Dipeolu1, M.A. and Ayinmode, A.B. (2014) Cryptosporidium infection in cattle in Ogun state, Nigeria. Sokoto J. Vet. Sci., 12(2): 52-56.

27. Mirzai, Y., Yakchali, M. and Mardani, K. (2014) Cryptosporidium parvum and Cryptosporidium andersoni infection in naturally infected cattle of Northwest Iran. Vet. Res. Forum., 5(1): 55-60.

28. Oskouei, M.M., Fallah, E., Ahmadi, M., Safaiyan, A., Bakhtiyari, S., Naserifar, R. and Dousti, M. (2014) Molecular and parasitological study of Cryptosporidium isolates from cattle in Ilam, West of Iran. Iran. J. Parasitol., 9(3): 435-440.

29. Ranjbar, R. and Fattahi, R. (2017) Prevalence of Cryptosporidium spp. in calves under one year old in Ilam county (Iran), from March 2014 to February 2015. Electron. Physician, 9(6): 4631-4635.

30. Al-Robaiee, I. and Al-Farwachi, M. (2014) Direct ELISA aided coprological diagnosis of Cryptosporidium parvum infection in diarrheic neonatal calves in Mosul city, Iraq. J. Adv. Vet. Anim. Res., 1(1): 8-10.

31. Huang, J., Yue, D., Qi, M., Wang, R., Zhao, J., Li, J., Shi, K., Wang, M. and Zhang, L. (2014) Prevalence and molecular characterization of Cryptosporidium spp. and Giardia duodenalis in dairy cattle in Ningxia, Northwestern China. BMC Vet. Res., 10(1): 292.

32. Qi, M., Wang, H., Jing, B., Wang, D., Wang, R. and Zhang, L. (2015) Occurrence and molecular identification of Cryptosporidium spp. in dairy calves in Xinjiang, Northwestern China. Vet. Parasitol., 212(3-4): 404-407.

33. Zhong, Z., Dan, J., Yan, G., Tu, R., Tian, Y., Cao, S., Shen, L., Deng, J., Yu, S., Geng, Y., Gu, X., Wang, Y., Lui, H. and Peng, G. (2018) Occurrence and genotyping of Giardia duodenalis and Cryptosporidium in pre-weaned dairy calves in central Sichuan province, China. Parasite, 25(13): 45

34. Liang, N., Wu, Y., Sun, M., Chang, Y., Lin, X., Yu, L., Hu, S., Zhang, X. and Zhang L. (2019) Molecular epidemiology of Cryptosporidium spp. in dairy cattle in Guangdong province, South China. Parasitology, 146(1): 28-32.

35. Nguyen, S.T., Nguyen, D.T., Le, D.Q., Hua, L.N.L., Nguyen, T.V., Honma, H. and Nakai, Y. (2007) Prevalence and first genetic identification of Cryptosporidium spp. in cattle in central Viet Nam. Vet. Parasitol., 150(4): 357-361.

36. Khin, K.L. (2007) Prevalence of Cryptosporidium, Giardia and other Gastrointestinal Parasites in Dairy Calves in Mandalay, Myanmar. MSc Thesis, Chiang Mai University and Freie Universität Berlin. Available from: http://cmuir. cmu.ac.th/jspui/handle/6653943832/35814. Last accessed on 17-09-2019.

37. Nan, J.Y., Anson, V., Koehler, J., Ebner, T., Kai, T., Yvonne, A.L., Lim, R. and Gasser, B. (2016) Molecular analysis of Cryptosporidium from cattle from five states of Peninsular Malaysia. Mol. Cell. Probes, 30(1): 39-43.

38. Joute, J.R., Gill, J.P.S. and Singh, B.B. (2016) Prevalence and molecular epidemiology of Cryptosporidium parvum in dairy calves in Punjab (India). J. Parasit. Dis., 40(3): 745-749.

39. Xiao, L. and Ryan, U.M. (2004) Cryptosporidiosis: An update in molecular epidemiology. Curr. Opin. Infect. Dis., 17(5): 483-490.

40. Radfar, M.H., Molaei, M.M. and Baghbannejad, A. 
(2006) Infection rate of Cryptosporidium spp. Oocysts in dairy calves in Kerman, Southeastern Iran. Iran. J. Vet. Res., 7(2): 81-84.

41. Thompson, R.C., Palmer, C.S. and O'Handley, R. (2008) The public health and clinical significance of Giardia and Cryptosporidium in domestic animals. Vet. J. Sep., 177(3): 309-310.

42. Kvac, M., Hromadova, N., Kvetonova, D., Rost, M. and Sak, B. (2011) Molecular characterization of Cryptosporidium spp. in pre-weaned dairy calves in the Czech Republic: Absence of C. ryanae and management-associated distribution of C. andersoni, C. bovis and C. parvum subtypes. Vet. Parasitol., 177(3-4): 378-382.

43. Ryan, U., Fayer, R. and Xiao, L. (2014) Cryptosporidium species in humans and animals: Current understanding and research needs. Parasitology, 141(13): 1667-1689.

$* * * * * * * *$ 